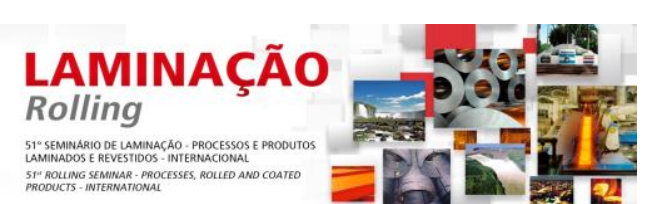

\title{
DESENVOLVIMENTO DO PINO DE CISALHAMENTO ELETRÔNICO NO LAMINADOR 2 (TL2)*
}

\author{
Rodrigo Citrangulo Daniel Luiz' \\ Daniel Guimarães Leão² \\ Leonardo Henrique Woitowicz ${ }^{3}$
}

\section{Resumo}

Este trabalho tem como objetivo demonstrar por meio de estudos técnico- científicos e de casos, como foram eliminadas as falhas devido a quebras dos elementos de proteção de sistemas de transmissão de torque (pinos de cisalhamento) no trem Laminador 2 (TL2) da Arcelormittal Piracicaba. A quebra de pinos de cisalhamento no TL2 são uma constante desde o inicio da operação do Laminador 2, sendo que diversas tentativas foram feitas no sentido de eliminar as quebras porem sem sucesso, o que demonstrou a necessidade de uma abordagem metodológica do problema. Este estudo, baseado na analise dos projetos dos equipamentos envolvidos e das praticas de manutenção adotada, orientou o redimensionamento dos elementos de proteção do sistema de transmissão de torque e o desenvolvimento de um novo sistema de proteção, utilizando o drive do motor para fazer a segurança do sistema de transmissão além da revisão e implantação de novas rotinas de manutenção nos equipamentos. O resultado obtido demonstrou a importância do profundo conhecimento tanto do projeto do equipamento quanto da avaliação e conhecimento empírico da manutenção de campo, conjunto este de informações que é indispensável para se garantir o desempenho dos equipamentos permitindo uma produção livre de imprevistos.

Palavras-chave: Pino de cisalhamento; Seis Sigma; PDCA.

\section{DEVELOPMENT OF ELECTRONIC PIN SHEAR OF ROLLING MILL 2}

\begin{abstract}
This paper main objective is to demonstrate how the break of protection elements of torque transmissions systems (shear pin) was done at ArcelorMittal Piracicaba through technical scientific studies of several cases. The breaks of shear pins at the intermediate mill are constant since the beginning of the operation of Rolling Mill 2. Several attempts were made trying to eliminate the breaks, but all unsuccessfully, what demonstrate a necessity of a methodological approach of the problem. This study, based on the analysis of the projects of the equipments involved and the maintenance practices, lead the way to re-dimension the protection elements of the torque transmission and the development of a new protection system, using the motor drive system to the security of the transmission system and to apply new maintenance routines on the equipments. The result achieved have shown how important it is to have full understanding of the equipment project and the maintenances routines for assuring a production free from unpredicted events.
\end{abstract}

Keywords: Production pace; Six Sigma; Productivity; Shear pin.

Engenheiro Mecânico da ArcelorMittal Piracicaba, São Paulo, Brasil.

2 Engenheiro Metalurgista da ArceloMittal Piracicaba, São Paulo, Brasil.

3 Gerente de Laminação da ArcelorMittal, Piracicaba, São Paulo, Brasil.

* Contribuição técnica ao $51^{\circ}$ Seminário de Laminação - Processos e Produtos Laminados e Revestidos, 28 a 31 de outubro de 2014, Foz do Iguaçu, PR, Brasil. 


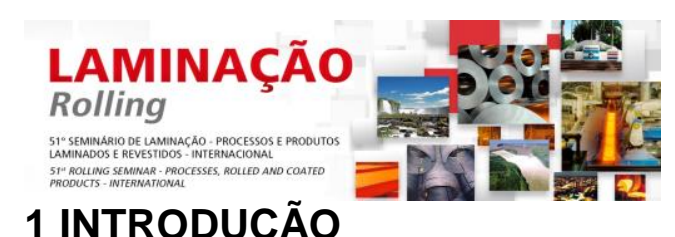

Este trabalho foi realizado no laminador 2 (TL2), da usina ArcelorMittal Piracicaba, SP. Um laminador dedicado a produzir vergalhão em barras retas de 8,0 a $40,0 \mathrm{~mm}$ de diâmetro, podendo atingir uma produção de 500kton/ano.

Teve seu início de produção em meados do ano de 2004, onde um fator que se mostrou negativo foi as constantes quebras dos pinos de cisalhamento do trem desbastador e intermediário, como mostra a figura 1.

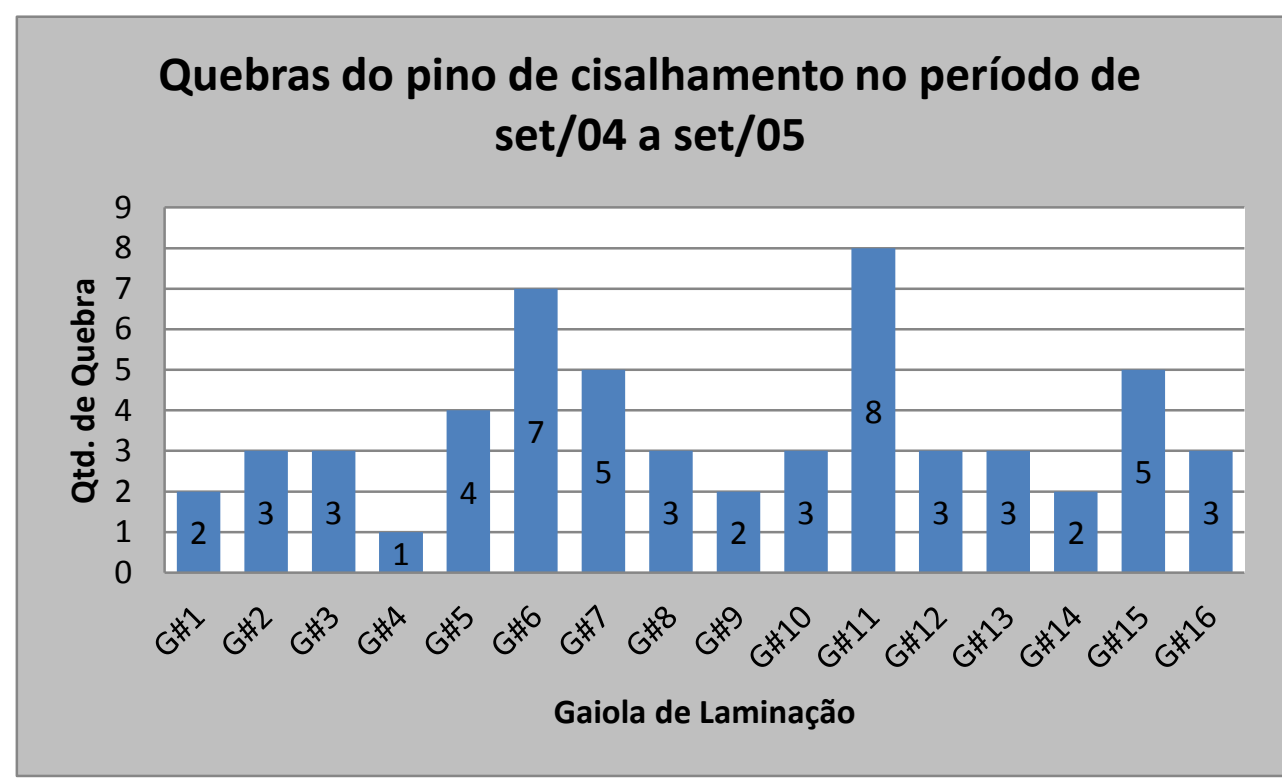

Figura 1. Distribuição de ocorrência de quebra por cadeira de laminação.

O pino de cisalhamento atua como uma proteção de todo o sistema de transmissão de torque e movimento, no caso da ocorrência de um sobre torque ele se rompe, desta forma evita um dano maior em equipamentos de maior importância, como por exemplo, um redutor ou um motor. No sistema de transmissão do TL2, figura 2, o pino de cisalhamento esta montado de forma a fazer a união entre o acoplamento do redutor e o acoplamento do motor, conforme figura 3.

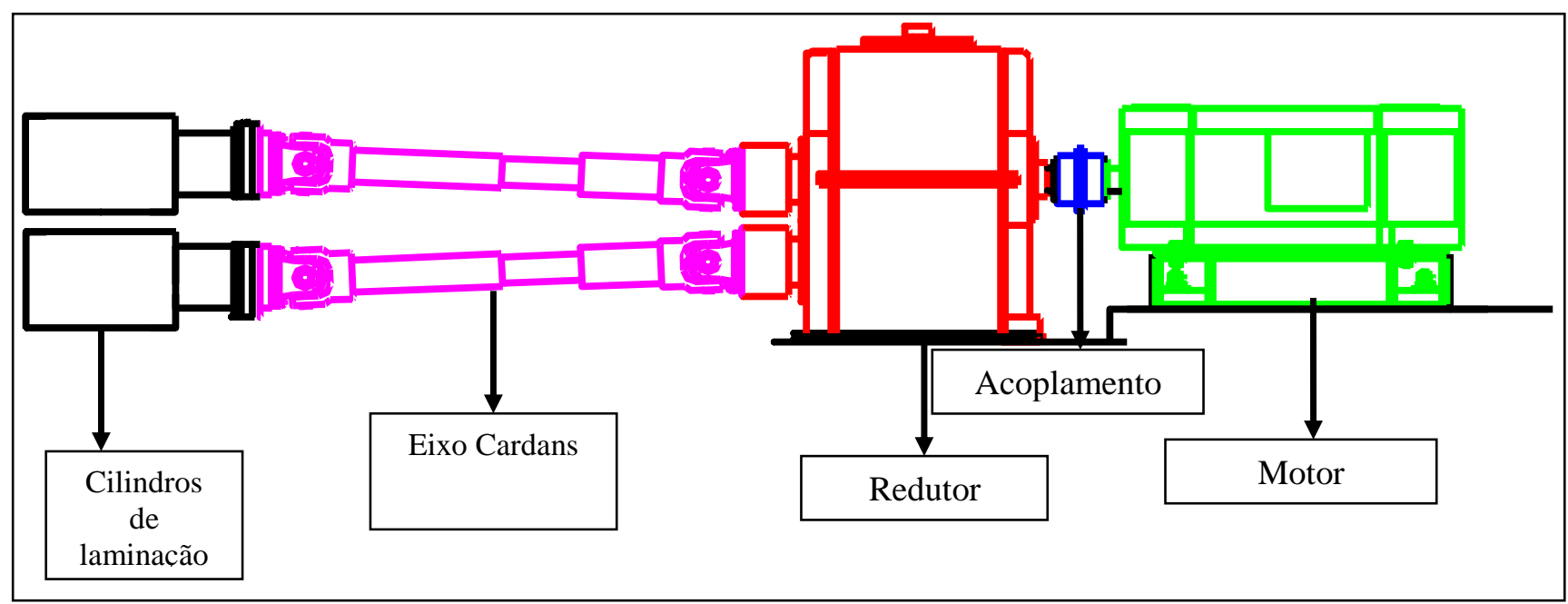

Figura 2. Desenho simplificado do sistema de transmissão do trem TL2.

* Contribuição técnica ao $51^{\circ}$ Seminário de Laminação - Processos e Produtos Laminados e Revestidos, 28 a 31 de outubro de 2014, Foz do Iguaçu, PR, Brasil. 


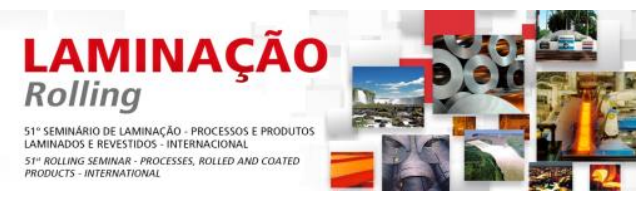

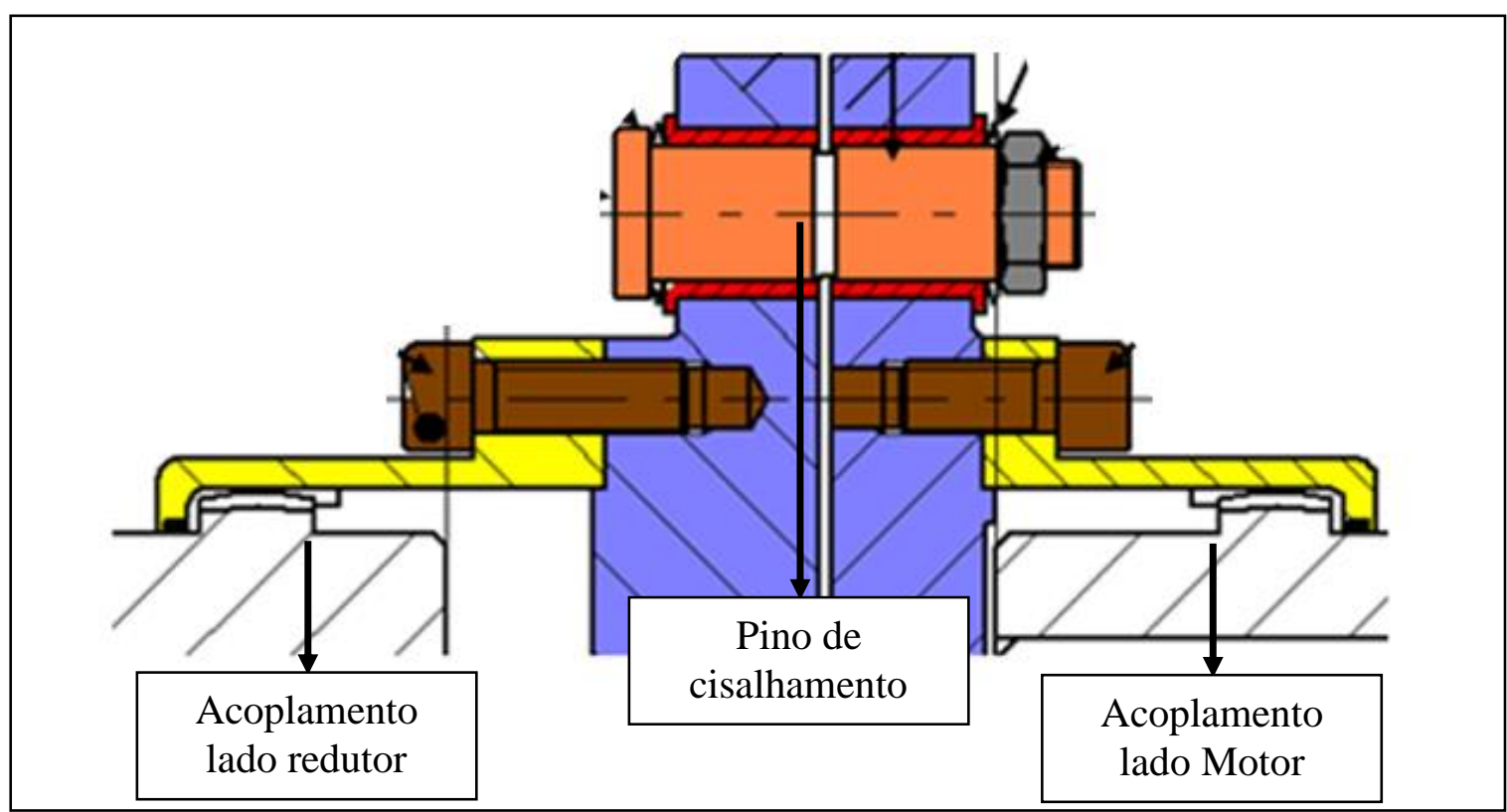

Figura 3. Desenho simplificado da montagem do pino de cisalhamento.

No inicio as quebras que ocorreram foram tratadas como algo esporádico, porém como as quebras ocorriam com uma frequência maior e em gaiolas distintas, 0 problema se tornou objeto de estudo. O uso da metodologia PDCA [2], foi aplicado em três períodos, a cada ciclo da metodologia nós atingíamos um bom resultado, porém não era um resultado sustentável e somente no terceiro ciclo do PDCA o resultado foi obtido de forma sustentável, o passo a passo de como nós utilizamos a metodologia será explicado nos capítulos a seguir.

\section{MATERIAIS E MÉTODOS}

A realização desse trabalho contou com o auxílio do PDCA na etapa inicial, a utilização do Mapa de Processo foi de especial importância por trazer a todos os envolvidos no projeto clareza sobre as variáveis de atuação e principalmente os ruídos envolvidos.

As ações implementadas garantiram eliminação da quebra dos pinos de cisalhamento trazendo maior estabilidade para o processo.

Para o primeiro ciclo do PDCA [1] a primeira etapa desenvolvida no trabalho foi mapear as variáveis que diretamente se relacionam com a quebra do pino de cisalhamento. Como vimos na figura 1, as quebras ocorriam em todas as gaiolas de do desbaste e intermediário. Nesta etapa do trabalho foi efetuado um estudo dos projetos dos equipamentos e dos elementos de proteção com o objetivo de detectar possíveis falhas. Abaixo o diagrama de Ishikawa, figura 4, através do qual foram estudadas e destacadas as principais causas.

* Contribuição técnica ao $51^{\circ}$ Seminário de Laminação - Processos e Produtos Laminados e Revestidos, 28 a 31 de outubro de 2014, Foz do Iguaçu, PR, Brasil. 


\section{LAMINAÇÃO Rolling
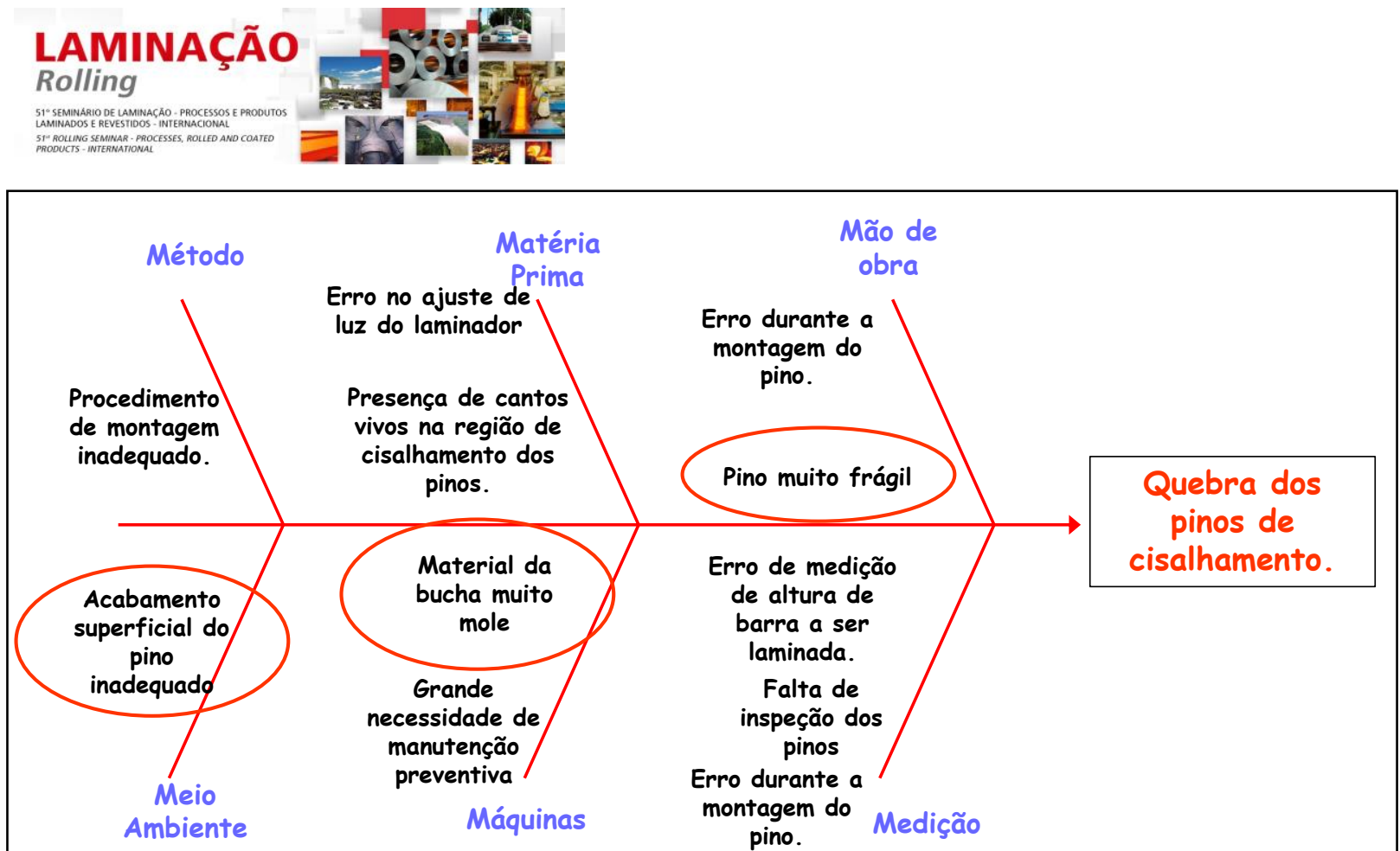

Figura 4. Diagrama de Ishikawa

Após a identificação das principais causas, foi elaborado o plano de ação e a sua conclusão foi no mês 11/2006, na figura 5 podemos notar a quantidade de quebra dos pinos de cisalhamento ao longo de dois anos após a partida do TL2, no período do mês de outubro de 2006, foram implementadas ações como:

- Melhoramento do acabamento superficial do pino de cisalhamento.

- Alterado material da bucha de latão para aço.

- Aumentado a seção transversal da região de cisalhamento do pino.

$\mathrm{Na}$ figura 6 podemos verificar o resultado das ações após a realização do plano de ação.

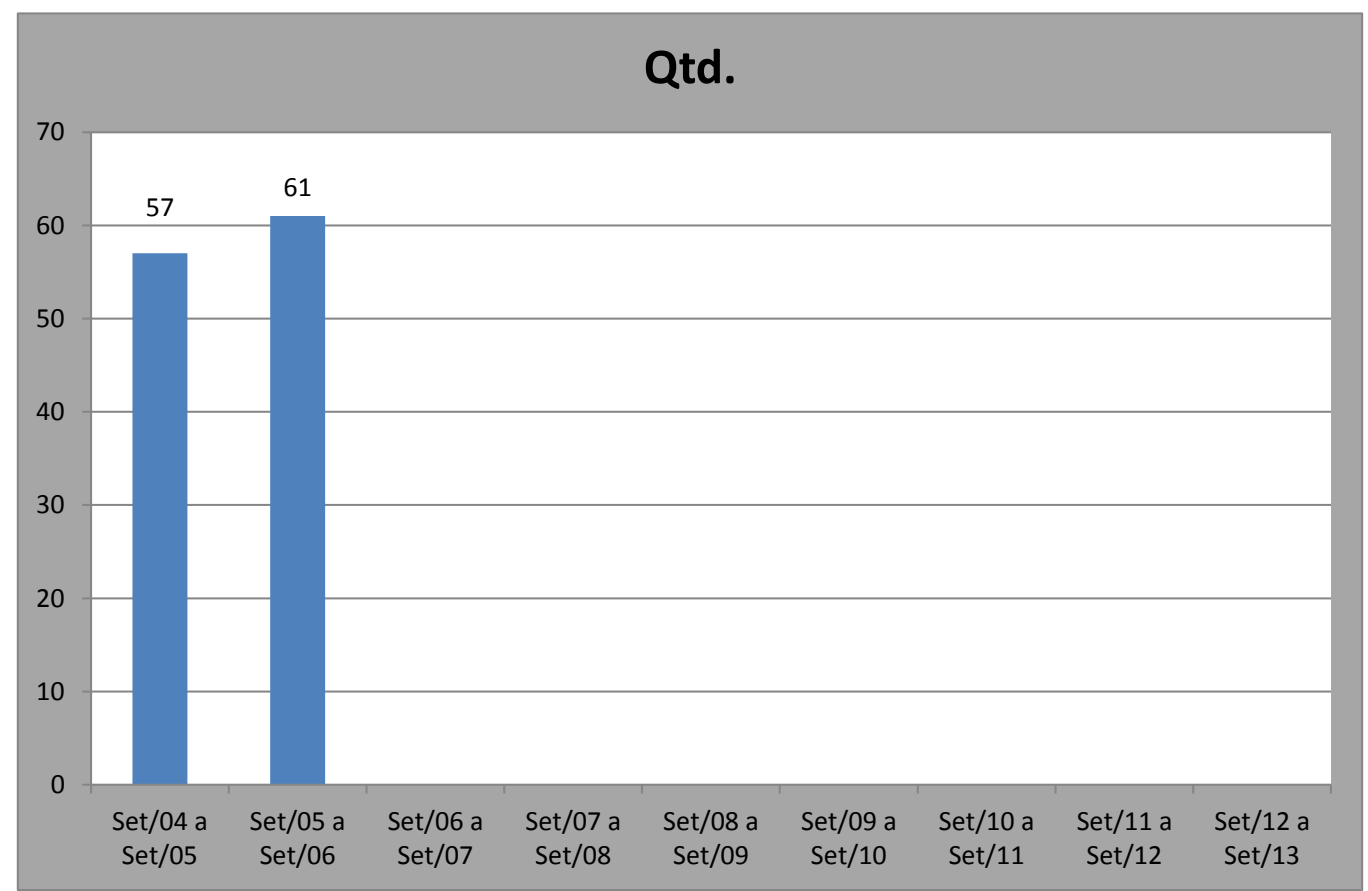

Figura 5. Gráfico evolutivo da quantidade de quebras dos pinos de cisalhamento

* Contribuição técnica ao $51^{\circ}$ Seminário de Laminação - Processos e Produtos Laminados e Revestidos, 28 a 31 de outubro de 2014, Foz do Iguaçu, PR, Brasil. 


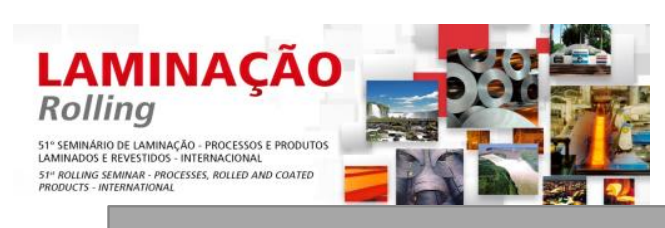

Qtd.

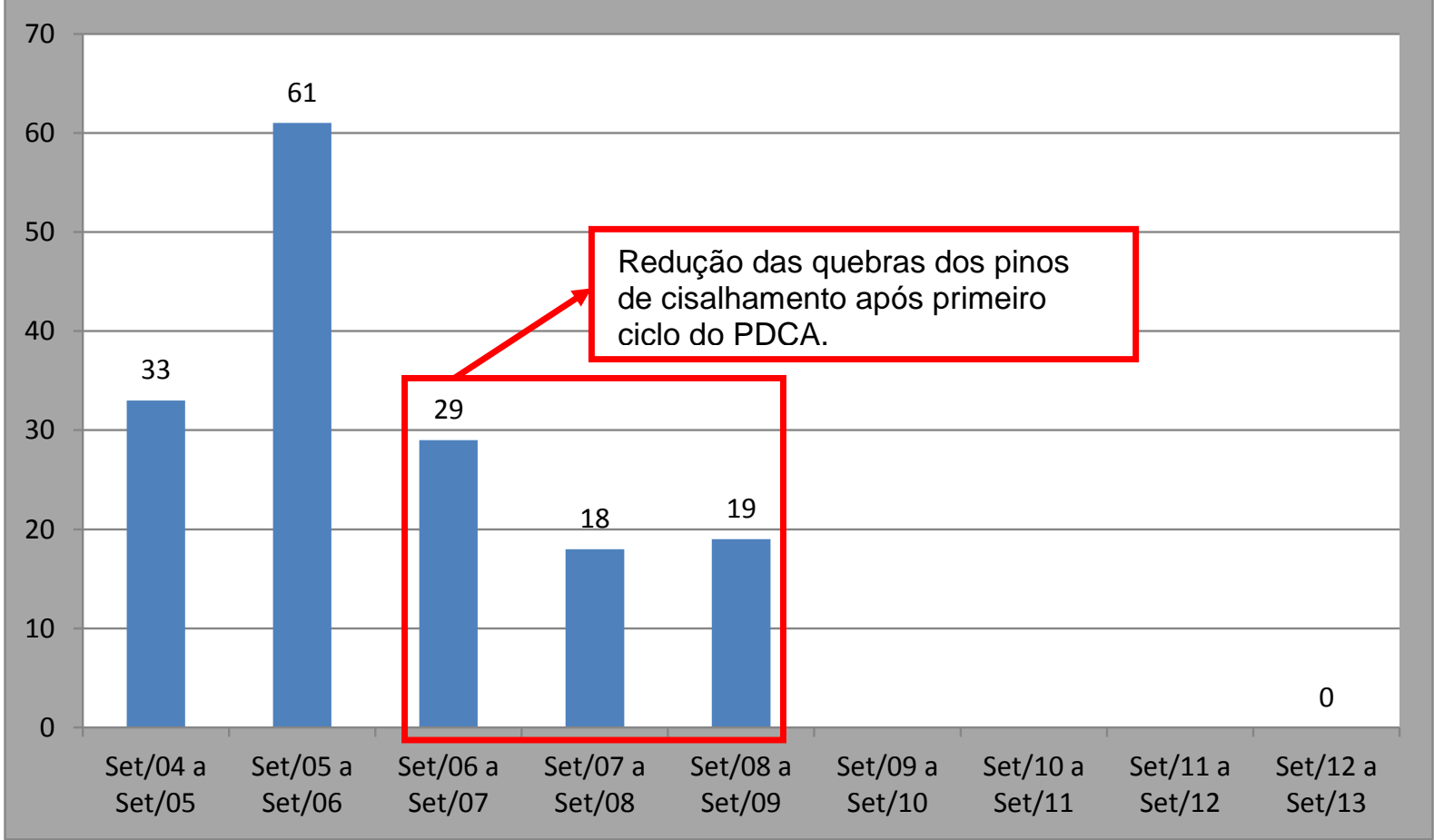

Figura 6. Gráfico de evolução após a realização do plano de ação.

Durante aproximadamente três, outros problemas de maiores prioridades surgiram, e o problema da quebra dos pinos de cisalhamento passou a não ser mais um problema prioritário. Porém em meados do ano de 2009, um novo debate e estudo sobre como resolver o problema de quebra de pinos de cisalhamento voltou a tona, novamente a metodologia do PDCA foi executada.

Para esta nova etapa foi mapeada as variáveis que diretamente se relacionam com a quebra do pino de cisalhamento. As principais são: temperatura do tarugo, diâmetro dos discos de laminação, redução em altura, adequação e processo de montagem do pino de cisalhamento.

Dentre estas variáveis, descarta-se a redução em altura, pois o controle de altura é realizado de forma sistemática garantindo sempre as alturas padrão, dentro da faixa de tolerância.

Passamos então a coletar dados referentes à temperatura dos tarugos, diâmetro dos discos e torque de laminação, após uma quebra do pino de cisalhamento, para coletas dos dados foram definidas algumas premissas, são elas:

- registrar a menor temperatura do tarugo em um intervalo de 24 horas;

- registrar o maior torque da cadeira em que houve quebra do pino em um intervalo de 24 horas; e

- registrar qual o valor do diâmetro do cilindro que estava em uso durante as 24 horas que antecederam a quebra do pino de cisalhamento.

Na Arcelormittal Piracicaba estes dados são arquivados e suas consultas são de fácil acesso, o que possibilitou a analise de todas as variáveis acima citadas em um determinado período. Foi realizada a compilação dos dados referente ao período de Julho de 2008 á Julho de 2009, e transportada na forma gráfica.

A Figura 7 mostra em quais temperaturas de tarugo houve a quebra do pino de cisalhamento, desta forma fica claro que a quebras analisadas não estão relacionadas com a temperatura do tarugo.

* Contribuição técnica ao $51^{\circ}$ Seminário de Laminação - Processos e Produtos Laminados e Revestidos, 28 a 31 de outubro de 2014, Foz do Iguaçu, PR, Brasil. 


\section{LAMINAÇÃO \\ Rolling}

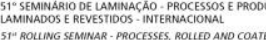

De acordo com Wusatowski [3], a figura 8 mostra em quais diâmetros de cilindro houve quebra do pino de cisalhamento, e, como a quebra ocorre em diâmetros distintos também podemos afirmar que nestes casos a quebra não está relacionada com diâmetro de cilindro.

A figura 9 mostra o nível de torque de laminação nas 24h antes da ocorrência de quebra, através do qual também se pode afirmar que não houve quebra relacionada a sobre torque de laminação. Na figura 9 onde se lê ((Max. 4153) 2875), por exemplo, significa que o máximo torque que o pino suporta é de $4153 \mathrm{Nm}$ e o máximo torque que o pino foi submetido no período de avaliação foi de $2875 \mathrm{Nm}$.

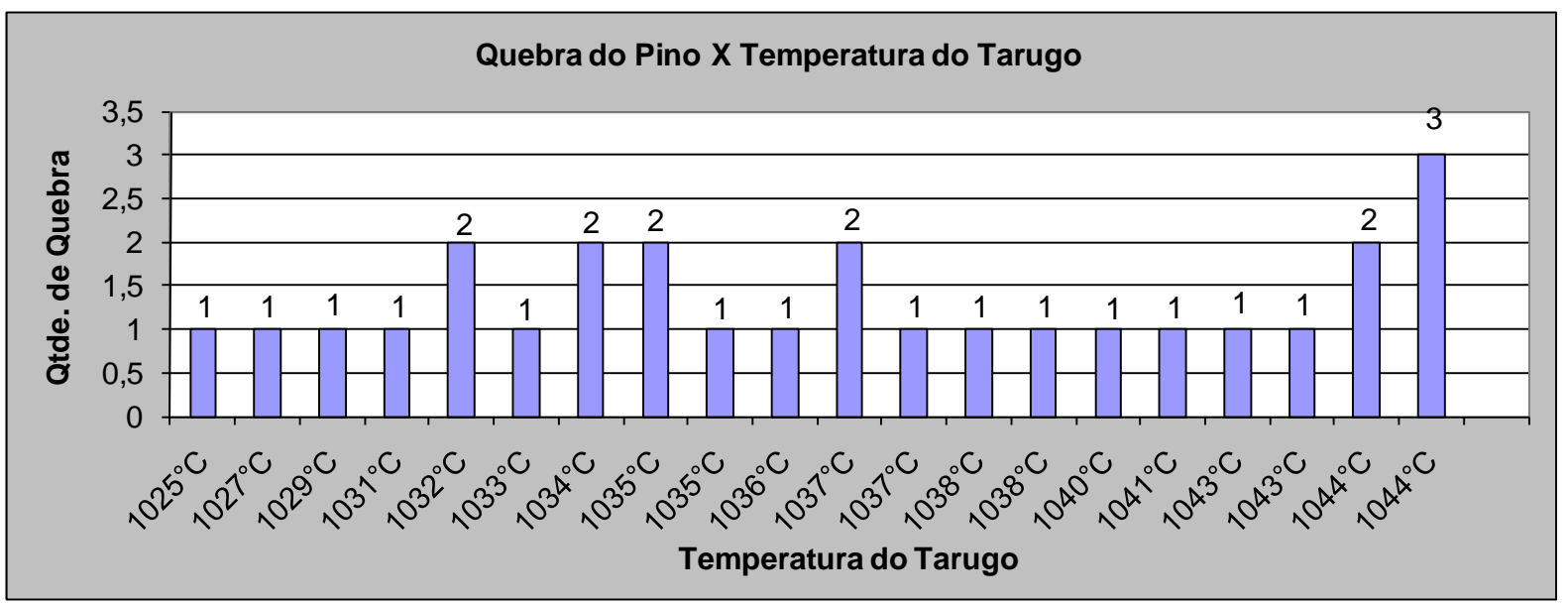

Figura 7. Quebra do pino X Temperatura do tarugo.

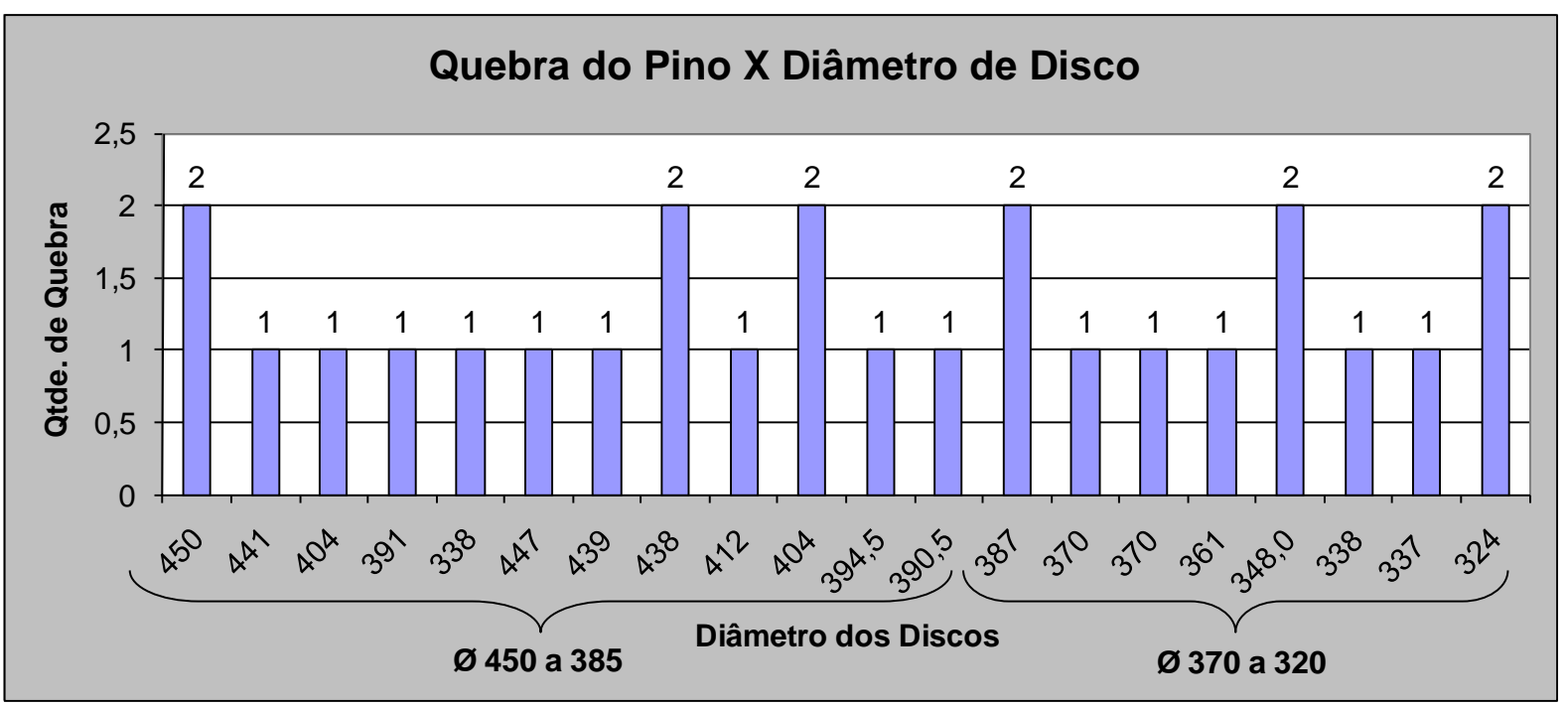

Figura 8. Quebra do pino X diâmetro de disco de laminação.

* Contribuição técnica ao $51^{\circ}$ Seminário de Laminação - Processos e Produtos Laminados e Revestidos, 28 a 31 de outubro de 2014, Foz do Iguaçu, PR, Brasil. 


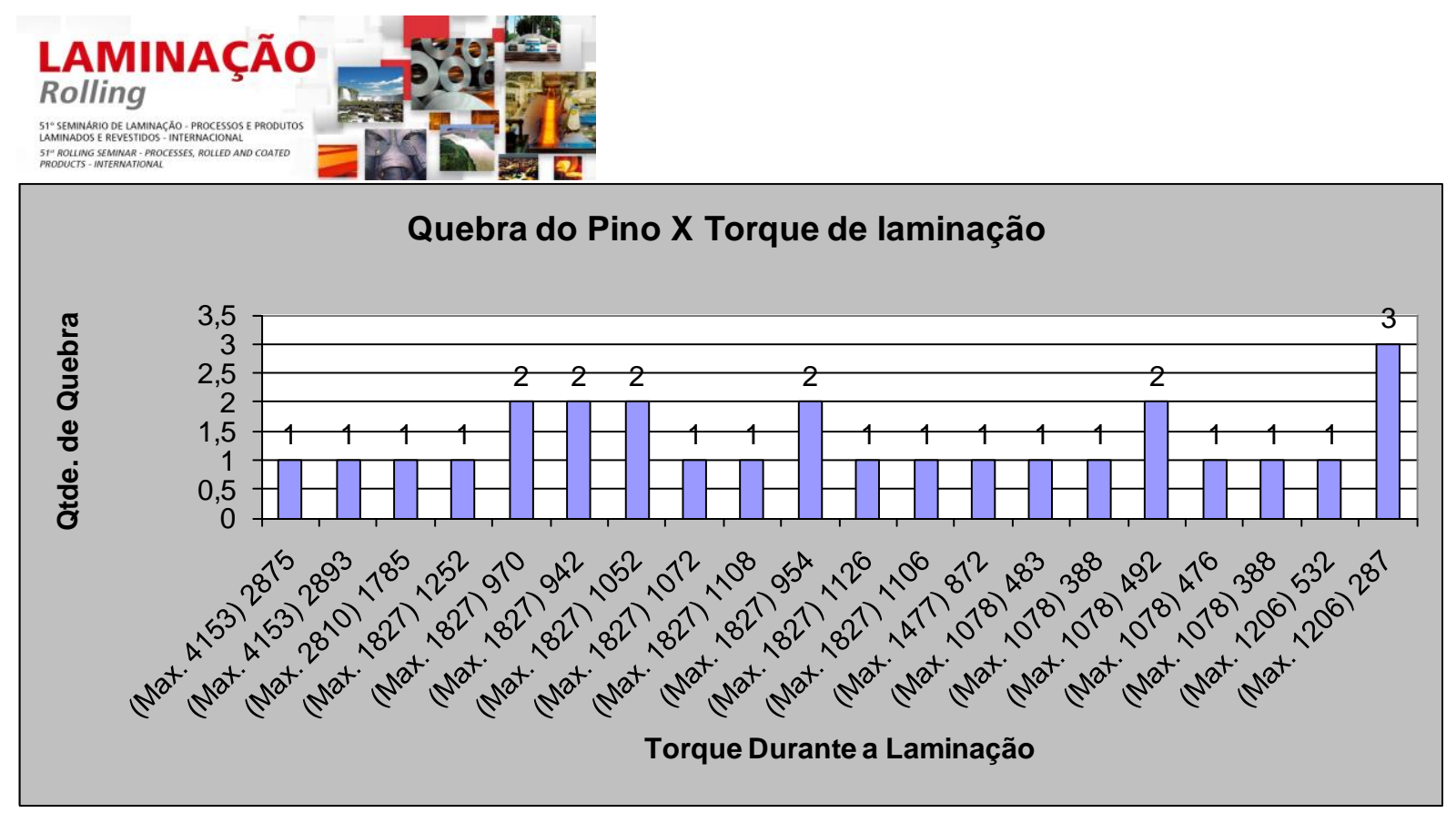

Figura 9. Quebra do pino X torque de laminação

Mediante a análise, pode-se constatar que as quebras analisadas não tem nenhuma ligação com a temperatura do material, diâmetro do cilindro e torque de laminação. Nesta etapa do trabalho foi efetuado um estudo dos projetos dos equipamentos e dos elementos de proteção com o objetivo de detectar possíveis falhas. Abaixo o diagrama de Ishikawa, figura 10, através do qual foram estudadas e destacadas as principais causas.

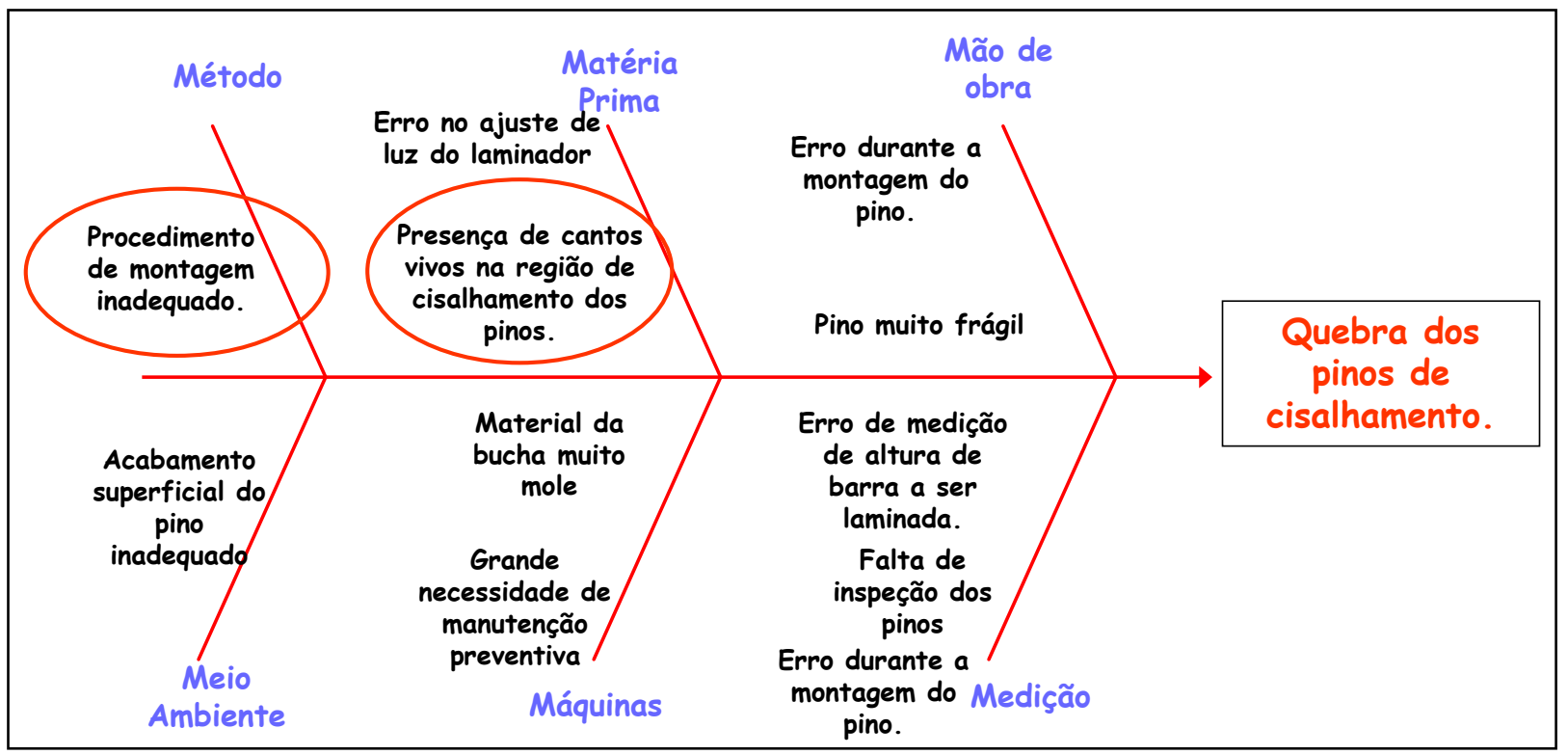

Figura 10. Diagrama de Ishikawa

Ao analisar as principais causas, notou-se que em algumas quebras os pinos de cisalhamento apresentavam um inicio de fadiga na região de canto vivo do pino, conforme figura 11.

De acordo com Antunes [2] este canto vivo é um acumulador de tensão que poderia estar fragilizando o material, e decorrente desta análise houve uma alteração no desenho de modo a eliminar o canto vivo. 


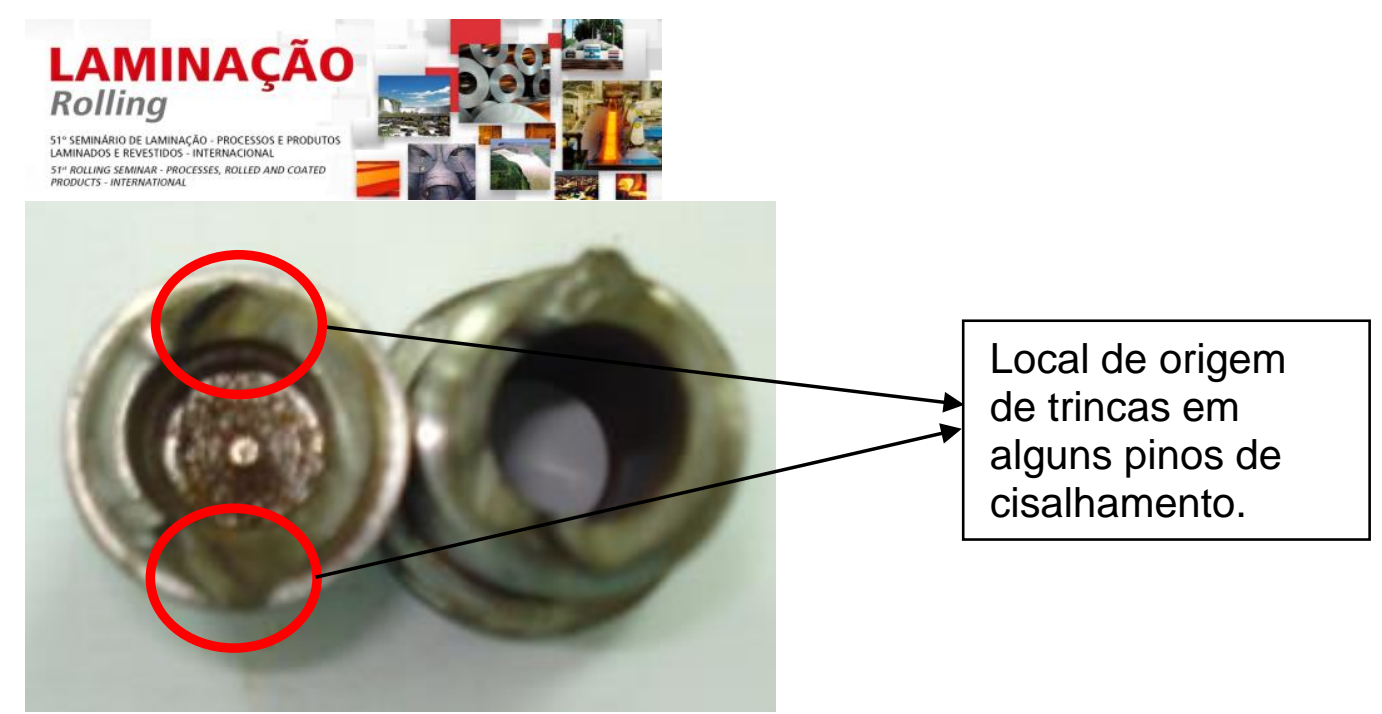

Figura 11, pino de cisalhamento após quebra.

Na próxima etapa do projeto foi feito o estudo para determinar o correto torque de aperto a ser aplicado no pino de cisalhamento durante sua montagem.

Este conceito é utilizado em uma infinidade de itens fixadores destinados a uniões de peças, tais como pino com porcas, pinos com porcas prisioneiras, pinos prisioneiros, etc.

A junção de acoplamentos por meio de pinos de cisalhamento é vantajosa, pois permite a manutenção e oferece várias formas de utilização, como transmissão de força, ajustagem, movimentos, etc.

Porém, as junções por pinos e porcas sujeitas a vibrações, afrouxam e, portanto requerem dispositivos de segurança para os seus travamentos. Exemplo de dispositivos de segurança: arruelas com travas, contraporcas, trava química, etc.

O dimensionamento, na realidade, é uma seleção dos elementos de fixação, uma vez que os pinos e porcas são elementos padronizados e também comerciais.

As únicas especificações não padronizadas são a profundidade do furo roscado e o torque de aperto, que serão definidas para cada aplicação.

Em geral, os pinos são dimensionados ou à tração ou ao cisalhamento, sendo que estes casos ocorrem em formas diferentes de solicitação, e para o nosso caso estaremos realizando o dimensionamento para a tensão de cisalhamento.

Os pinos que fixarão as flanges do acoplamento trabalham com pré-carga, sob tensão e deverão ser corretamente dimensionados para não sofrerem deformações na montagem (torque de aperto).

Se não forem corretamente dimensionados, quando sofrerem o torque de aperto, não poderão ser reaproveitados em outra montagem porque sofrerão deformações longitudinalmente.

Observe no formulário abaixo que a força tangencial cortante " $F$ " depende fundamentalmente da força de aperto " $Q$ ", e por sua vez, a força de aperto " $Q$ " é bem maior que a força cortante " $F$ " razão pela qual se degolam facilmente os parafusos pequenos e geralmente não se apertam suficientemente os parafusos grandes.

Formulário

(01) $F=2 \times M t \times\left(\frac{F s}{z \times k}\right)$

(02) $M t=71620 \times \frac{N}{n}$

* Contribuição técnica ao $51^{\circ}$ Seminário de Laminação - Processos e Produtos Laminados e Revestidos, 28 a 31 de outubro de 2014, Foz do Iguaçu, PR, Brasil. 


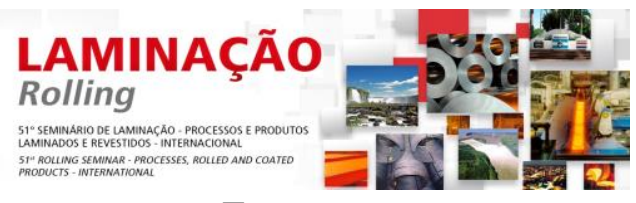

$$
\begin{aligned}
& \text { (03) } Q=\frac{F}{\operatorname{tg}(\alpha+\varphi)} \\
& \text { (04) } d_{1}=\sqrt{\frac{4 \times Q}{\pi \times \sigma_{a d}}} \\
& \text { (05) } \operatorname{tg} \alpha=\frac{p}{\pi \times d_{2}} \\
& \text { (06) } \sigma_{a d}=\frac{\sigma_{e}}{s} \\
& \text { (07) } \operatorname{tg}(\alpha+\varphi)=\frac{\operatorname{tg} \alpha+\operatorname{tg} \varphi}{1-\operatorname{tg} \alpha \times \operatorname{tg} \varphi}
\end{aligned}
$$

Onde: $F s=$ fator de serviço $(F s=1,25-1,35)$

$\mathrm{F}=$ força cortante agente no parafuso (kgf)

71620 = constante de transformação de unidade

$\mathrm{N}=$ potência a transmitir (CV)

$\mathrm{z}=$ número de parafusos

$\mathrm{k}=$ diâmetro da circunferência onde estão os parafusos $(\mathrm{cm})$

$\mathrm{n}=$ rotação do eixo (rpm)

$Q=$ carga cortante de cisalhamento

$\varphi=$ ângulo de atrito. Para contato aço / aço $=\operatorname{tg} \varphi=0,18$

$\alpha=$ ângulo de inclinação da hélice da rosca. Para rosca métrica com passo

e diâmetro médio definidos $\alpha \approx 2,5^{\circ}$

$\mathrm{p}=$ passo da rosca $(\mathrm{mm})$

$\mathrm{d}_{2}=$ diâmetro médio da rosca

$\mathrm{d}_{1}=$ diâmetro do núcleo da rosca

$\sigma_{\text {ad }}=$ tensão normal admissível do material

$\sigma_{e}=$ tensão de escoamento do material (tabelado)

$\mathrm{s}=$ coeficiente de segurança, $(3,5$ a 6,5$)$.

Cálculo do torque de aperto.

(08) $T=y \times Q \times d e$

Onde: $\mathrm{T}=$ torque de aperto (kgf.cm)

de = diâmetro externo da rosca $(\mathrm{mm})$

$\mathrm{y}=$ coeficiente de torque:

$0,1=$ rosca lubrificada

$0,35=$ rosca fina

$0,2=$ valor usual para rosca normal.

- Exemplo:

Determinar o correto aperto do pino de cisalhamento, para que o mesmo possa atuar de forma a suportar um torque de $20 \%$ a mais que o torque normal de laminação. $\mathrm{O}$ acionamento será feito por um motor de $612 \mathrm{CV}$ e com uma rotação base de $500 \mathrm{rpm}$, o material a ser utilizado possui um limite de escoamento de $8157,6 \mathrm{kgf} / \mathrm{cm}^{2}$, o torque máximo de laminação é de $42426,3 \mathrm{kgf} . \mathrm{cm}$ e o torque máximo do redutor é de $87662,88 \mathrm{kgf.cm}$. O sistema possui dois pinos de cisalhamento e o diâmetro onde estão alojados os pinos é de $18,75 \mathrm{~cm}$, o pino possui um diâmetro externo de $2,3 \mathrm{~cm}$ e diâmetro interno de $1,72 \mathrm{~cm}$.

* Contribuição técnica ao $51^{\circ}$ Seminário de Laminação - Processos e Produtos Laminados e Revestidos, 28 a 31 de outubro de 2014, Foz do Iguaçu, PR, Brasil. 
LAMINAÇÃO

Rolling

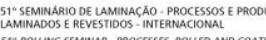

(06) $\sigma_{a d}=\frac{\sigma_{e}}{s}$ segundo Antunes $\mathrm{s}=2,25$

$(06) \sigma_{\mathrm{ad}}=\underline{8157,6} \quad \sigma_{\mathrm{ad}}=3625,6 \mathrm{kgf} / \mathrm{cm}^{2}$

2,5

$A_{a ́ r e a ~}=A_{\text {maior }}-A_{\text {menor }} \quad A_{\text {área }}=1,83 \mathrm{~cm}^{2} \quad F s=2,25$

$(02) \mathrm{Mt}=42426,3+20 \%=50911,56 \mathrm{kgf} . \mathrm{cm}^{2}$

(01) $F=2 \times M t \times\left(\frac{F s}{z \times k}\right)=2 \times 50911,56 \times\left(\frac{2,25}{2 \times 18,75}\right)=\mathrm{F}=6109,39 \mathrm{kgf}$

(03) $Q=6639,32 \mathrm{kgf}$

$\mathrm{de}=1,83 \mathrm{~cm}$

$y=0,2$

(08) $T=y \times Q \times d e=\mathrm{T}=24,32 \mathrm{kgf} . \mathrm{m}$

Na figura 12 podemos verificar o resultado das ações após a realização do plano de ação.

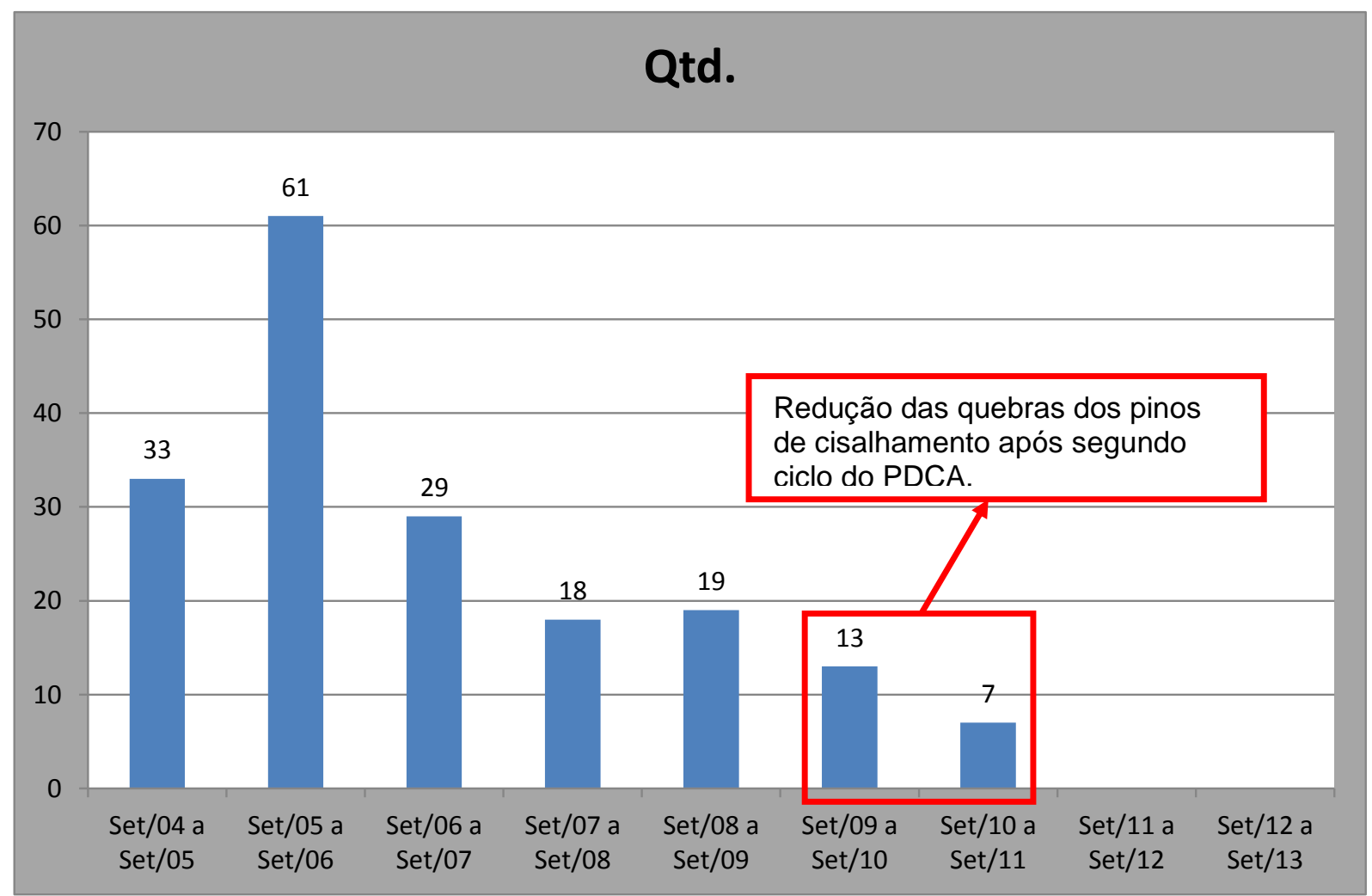

Figura 12. Gráfico de evolução após a realização do plano de ação.

Esta alteração apesar de apresentar um bom resultado, é necessário uma rotina de inspeção dos pinos e check do torque de aperto dos pinos de cisalhamento, porém

* Contribuição técnica ao $51^{\circ}$ Seminário de Laminação - Processos e Produtos Laminados e Revestidos, 28 a 31 de outubro de 2014, Foz do Iguaçu, PR, Brasil. 


\section{LAMINAÇÃO

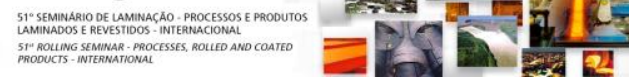

não tínhamos recurso necessário para absorver esta rotina e como mostra na figura 13, o índice de quebra dos pinos de cisalhamento voltou a ocorrer.

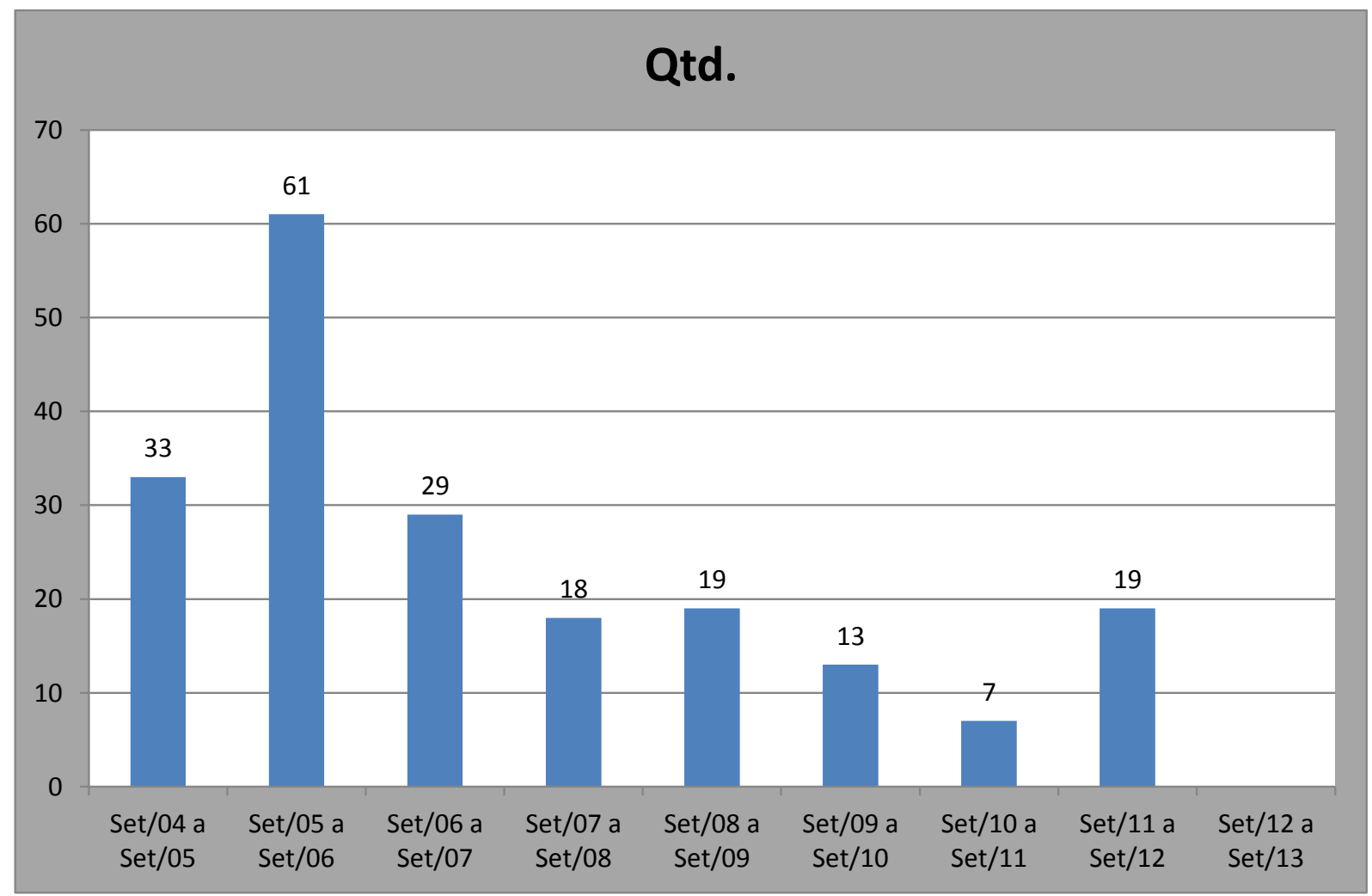

Figura 13. Gráfico de evolução de quebra dos pinos de cisalhamento

Durante o mês de Julho de 2012 demos inicio a terceira avaliação do problema que envolvia a quebra dos pinos de cisalhamento, sempre utilizando a metodologia PDCA [1], com a utilização da ferramenta Ishikawa, figura 14, foi possível identificar a possibilidade de um controle do torque automático, este controle do torque seria feito pelo drive de cada motor, esta indicação do torque do motor é um recurso que temos desde o início de produção do laminador no ano de 2004, porém nunca para utilizado para este objetivo, pois até o momento não se tinha ciência de qual eram as forças agindo sobre o pino de cisalhamento durante um processo de laminação, esta informação só foi conhecida após o estudo de forças e torque de aperto apresentado na segunda etapa do ciclo PDCA [1].

* Contribuição técnica ao $51^{\circ}$ Seminário de Laminação - Processos e Produtos Laminados e Revestidos, 28 a 31 de outubro de 2014, Foz do Iguaçu, PR, Brasil. 


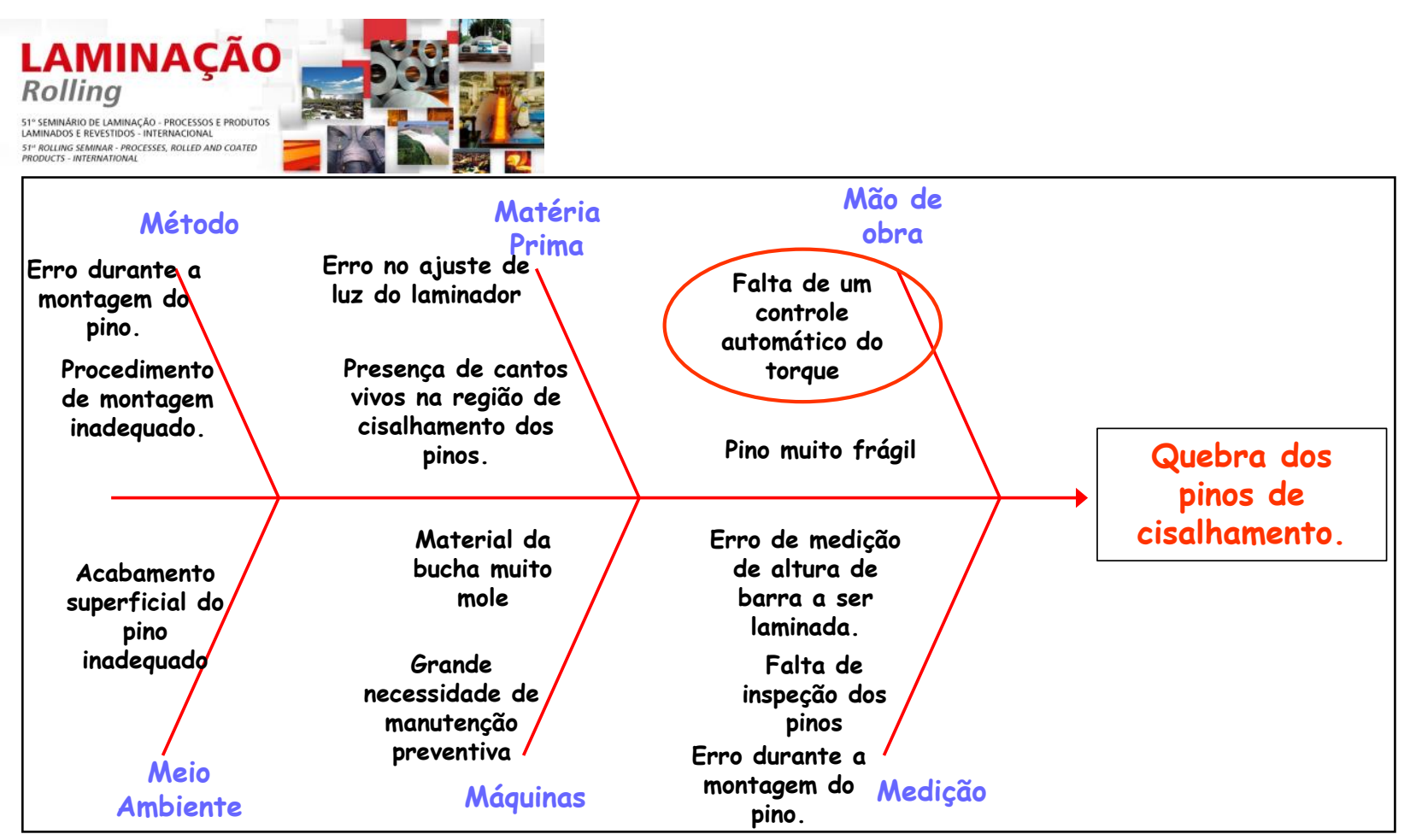

Figura 14. Diagrama de Ishikawa

Após a análise do diagrama de Ishikawa, e evidenciado a possibilidade de utilização do monitoramento do torque pelo drive de cada motor, foi iniciado um acompanhamento do torque de laminação para todas as famílias de bitolas, exemplo:

- Família de bitolas finas = barras de $9,5 \mathrm{~mm}$ á $10,0 \mathrm{~mm}$

- Família de bitolas médias = barras de 12,0mm á 16,0mm

- Família de bitolas grosas = barras de $18,0 \mathrm{~mm}$ á 25,0mm

- Família de bitolas extra grosas = barras de $32,0 \mathrm{~mm}$ á $40,0 \mathrm{~mm}$

A etapa de coletas de dados foi realizada durante 120 dias, e os registros de torque eram realizados de hora em hora, o que nos gerou aproximadamente 2900 dados, abrangendo todas as famílias de bitolas, conforme a figura 14, estes dados foram compilados e através destes dados foi desenvolvido uma lógica com três níveis de consequência:

a) Se durante a laminação ocorrer um sobre torque acima de $80 \%$, durante 5 segundos, um alarme no supervisório do laminador se gerado, alertando o operador sobre o problema.

b) Se durante a laminação ocorrer um sobre torque acima de $85 \%$, durante 5 segundos, um alarme no supervisório do laminador se gerado, alertando o operador sobre o problema e será bloqueado o desenfornamento do próximo tarugo.

c) Se durante a laminação ocorrer um sobre torque acima de $90 \%$, durante 0,2 segundos, um alarme no supervisório do laminador se gerado, alertando o operador sobre o problema e ocorrerá um desarme do motor da gaiola que apresentar este problema e o bloquei 0 desenfornamento do próximo tarugo.

\section{RESULTADOS}

As alterações foram realizadas durante o mês de Agosto de 20112. A partir desta data não ocorreram mais quebras do pino de cisalhamento, conforme figura 15,0 que demonstra a eficácia das medidas adotadas.

* Contribuição técnica ao $51^{\circ}$ Seminário de Laminação - Processos e Produtos Laminados e Revestidos, 28 a 31 de outubro de 2014, Foz do Iguaçu, PR, Brasil. 


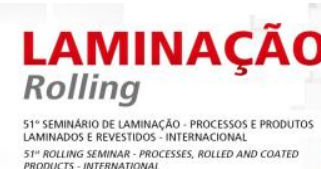

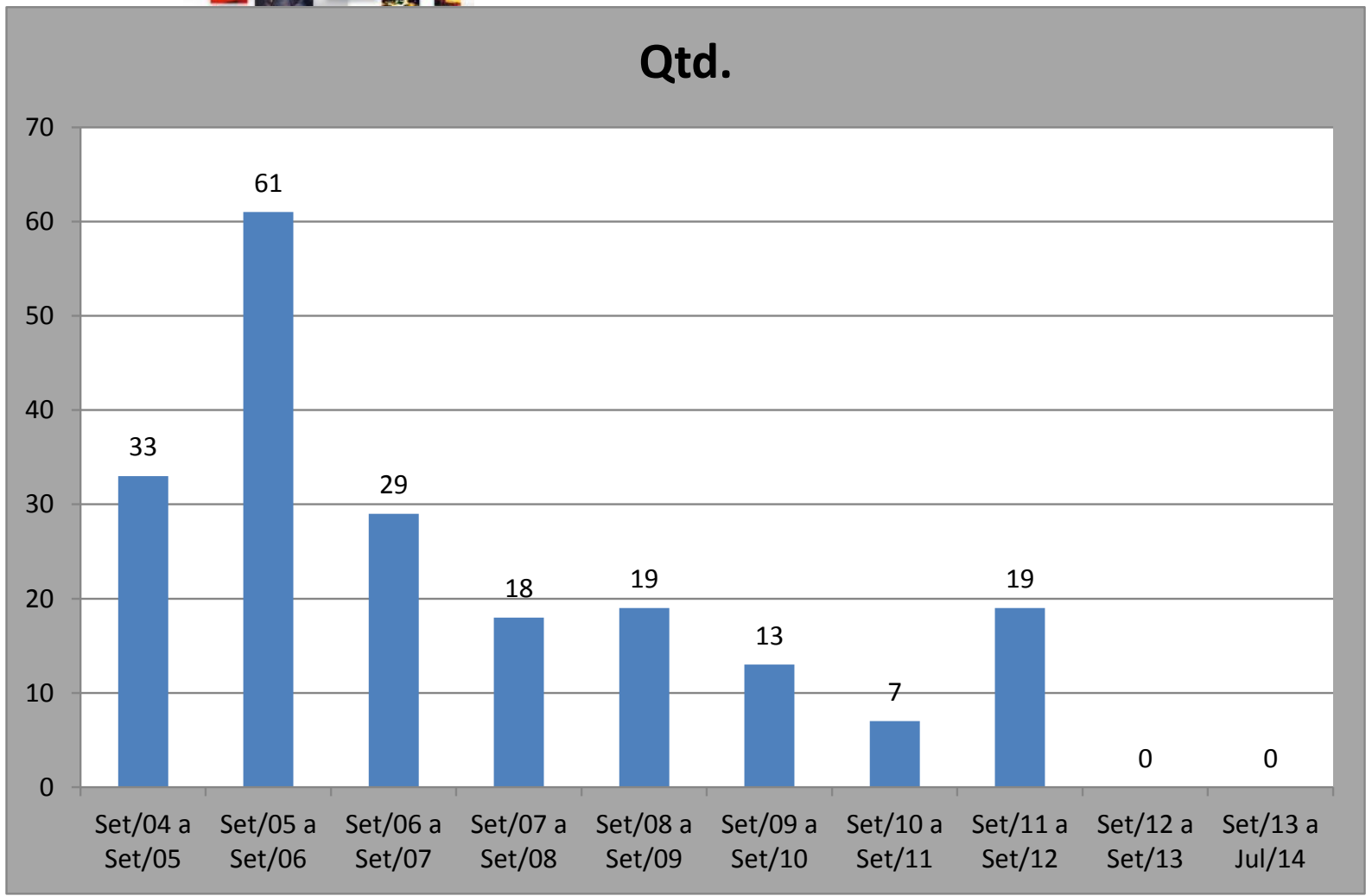

Figura 13. Gráfico de evolução de quebra dos pinos de cisalhamento

\section{CONCLUSÃO}

A produtividade de um laminador é fortemente afetada por paradas corretivas não programadas.

O redimensionamento e a nova metodologia de montagem dos pinos de cisalhamento trouxeram um grande ganho para o processo tornando-o mais confiável.

A simplicidade da solução proposta facilita ainda a manutenção do sistema de transmissão e reduz os custos decorrentes de interrupções, sucatas e reposição dos pinos.

\section{REFERÊNCIAS}

1 Perez-Wilson M. Seis Sigma: compreendendo o conceito, as implicações e os desafios. Rio de Janeiro: Qualitymark Ed., 1999.

2 Antunez I. Elementos de Máquina. 7ª edição Érica Ltda, 1997.

3 Wusatowski Z. Fundamentals of Rolling: 1르 edição, Pergamon 1969.

* Contribuição técnica ao $51^{\circ}$ Seminário de Laminação - Processos e Produtos Laminados e Revestidos, 28 a 31 de outubro de 2014, Foz do Iguaçu, PR, Brasil. 